\title{
Aproximações teórico-metodológicas entre a geografia e o cinema: a cidade-personagem
}

\section{Theoretical-methodological approaches between geography and cinema: the city-character}

Marcos Antônio da Silva Ferreira Doutorando em Geografia pelo Programa de Pós-Graduação em Geografia (ProPGeo) da Universidade Estadual do Ceará (UECE), bolsista CAPES e integrante do Laboratório de Estudos em Geografia Cultural (LEGEC), Brasil geo.marcosf@gmail.com

Otavio José Lemos Costa Professor Adjunto da Universidade Estadual do Ceará (UECE) Coordenador do Laboratório de Estudos em Geografia Cultural (LEGEC), Brasil otavio.costa@uece.br

\begin{abstract}
Resumo
Este artigo evoca os tensionamentos teóricos e metodológicos entre a ciência geográfica e a linguagem cinematográfica para compreender a cidade-personagem nos filmes de ficção. Para isso, buscou-se na transdisciplinaridade do conhecimento científico e na corporificação do saber as múltiplas interpretações geográficas proferidas nas e a partir das obras fílmicas. Mediante o confronto espacial e subjetivo estabelecidos entre o cinema e o espectador, o ato de se assistir a um filme torna-se, portanto, uma experiência geográfica. A cidade-personagem, produto da relação entre os demais personagens da trama com o espaço diegético, se expressa pela sua própria capacidade de representação de si a partir do outro, provocando, assim, a manifestação do lugar fílmico imbricado de afetos, metáforas, símbolos e significações.
\end{abstract}

Palavras-chave: Transdisciplinaridade; Arte; Narrativas Fílmicas; Lugar Fílmico.

\begin{abstract}
This article evokes the theoretical and methodological tensions between the geographical science and cinematic language to understand the city-character in fiction films. For this, the multiple geographical interpretations given in and from the film works were sought in the transdisciplinarity of scientific knowledge and the embodiment of knowledge. Through the spatial and subjective confrontation established between the cinema and the spectator, the act of watching a movie becomes, therefore, a geographical experience. The city-character, product of the relation between the other characters of the plot with the diegetic space, is expressed by its capacity of representation of itself from the other, thus provoking the manifestation of the filmic place imbricated of affections, metaphors, symbols and meanings.
\end{abstract}

Keywords: Transdisciplinarity; Art; Film Narratives; Filmic Place.

\section{INTRODUÇÃO}

É comum observarmos nos filmes, especialmente nas cenas filmadas em locais externos, as formas simbólicas e materiais da paisagem urbana cinemática. A arquitetura dos prédios, das praças, a dinâmica das ruas, as disposições intencionais e narrativas das cores em quadro e o som diegético que 
emana da urbe capturam nossa atenção e rapidamente nos deparamos imersos no universo cinematográfico apresentado em tela.

Como esquecer a melancólica Paris de Woody Allen, no filme "Meia-Noite em Paris" (2011), de tons amarelados e um saudosismo burguês de um tempo histórico irreversível; da Buenos Aires solitária, azulada e obsessiva em distanciar os seus protagonistas, no filme "Medianeras: Buenos Aires da Era do Amor Virtual” (Gustavo Taretto, 2011); da industrial e caótica Berlim no auge do seu desenvolvimento econômico, no filme "Berlim, Sinfonia de uma Grande Cidade" (Walther Ruttmann, 1927); ou mesmo da ruína reminiscente e violenta de Fengjie que Jia Zhang-Ke dispõe no longa "Em Busca da Vida" (2006).

As cidades, ao longo da história do cinema, assumiram papéis para além de simples locações filmicas para tornarem-se também personagens das suas próprias narrativas. Tal reflexão advém do principal questionamento que norteia o aporte teórico e metodológico deste trabalho: por que em alguns filmes a cidade pode ser compreendida enquanto personagens da trama? Quais os elementos filmicos que nos revelam a cidade-personagem? E como a ciência geográfica pode nos ajudar a interpretá-los?

Costa (2008) e Bruno (2002) argumentam que o cinema é uma arte predominantemente urbana por ter nascido na cidade e a partir do seu próprio desenvolvimento tecnológico e cultural. O que torna a atividade cinematográfica uma prática artística que é simultaneamente produto e agente produtor do imaginário urbano, seja no desenvolvimento das narrativas documentais, próximas do real, ou ficcionais, capazes de expressar imagens espaciais de lugares até então já existentes ou mesmo recriar novas experiências urbanas completamente singulares.

Dessa forma, especialmente na ficção, a cidade que o cinema evoca equipara-se mais com a do romancista do que a mesma planejada pelos urbanistas, arquitetos ou geógrafos. Tal afirmação se deve pelo fato de considerarmos o papel da transfiguração imagética que a câmera possui ao captar o movimento do real para as telas a partir do processo de montagem. Ou seja, o cinema, conforme Comolli (2008), além de não filmar o mundo, embora o altere em representação, é capaz de transformar a cidade em signo, "com múltiplos significados para além daqueles que o espaço urbano possui" (TAVARES, 2015, p. 256), dentre eles a de personagem na própria trama.

É através da narrativa, a arte de se contar algo, que o cinema desperta os múltiplos caminhos para se interpretar o urbano dentro, fora e para além do filme. O ato de descrever, prática potente do cinema de se construir uma narrativa, realiza-se a partir dos planos, cenas e sequências que compõem a imagem cinematográfica. A paisagem do filme torna-se, então, uma fábrica de sentidos e ilusões (OLIVEIRA JÚNIOR, 1999) capaz de expressar infinitos significados sobre a trama e os personagens até mais do que as palavras ou diálogos construídos nele.

E a própria ciência geográfica, com seus múltiplos olhares sobre a realidade ficcional e não ficcional, a partir dos seus conceitos e/ou categorias de análise, colabora veementemente na reflexão 
teórica acerca do espaço fílmico. É através da relação afetiva estabelecida entre os personagens com o lugar fílmico que a paisagem urbana cinemática, ou seja, a cidade, torna-se personagens da trama. Assim como Oliveira Júnior (1999) estabeleceu a chuva como personagem nos filmes "Antes da Chuva" (Milcho Manchevski, 1994) e "Blade Runner, O Caçador de Androides” (Ridley Scott, 1982), a "subida" da cidade-personagem do plano de fundo para o plano da narrativa está diretamente vinculada com as relações afetivas e geográficas estabelecidas nos filmes.

Há um forte desejo latente em produzir geografias a partir da arte cinematográfica. Buscamos, nos filmes, a potência geográfica presente na sua forma, experiência e discurso, explorando um universo de sensibilidades artísticas ainda pouco discutido na Geografia.

\section{ENTRE FRONTEIRAS DA TRANSDISCIPLINARIDADE: GEOGRAFIAS, IMAGINAÇÃO E ARTE}

Há, no âmbito dos estudos entre a Geografia e o cinema, um questionamento que constantemente é enunciado nos artigos, dissertações e teses daqueles que se aventuram em discutir os filmes, sejam eles curtas, médias e/ou longas-metragens documentais ou ficcionais: quais as interseções possíveis entre a ciência geográfica e a linguagem cinematográfica?

Tal questionamento, tão amplo e que demanda uma complexidade teórica e metodológica de reflexão, pode também ser reescrito de outra maneira: quais as interseções entre a ciência e a arte? Se pensarmos a Geografia na sua maturidade epistemológica como ciência e os filmes enquanto produtos artísticos, podemos tensionar esses dois saberes e práticas em busca de uma transdisciplinaridade? Há realmente uma necessidade de separá-los em dois grupos aparentemente tão distintos: ciência e arte? A ciência também não pode ser considerada como um devir artístico?

Não há como adentrarmos na fronteira nebulosa estabelecida historicamente entre a ciência e a arte sem pautarmos a modernidade ${ }^{1}$ enquanto precursora deste movimento dualista e asséptico que atravessou e suplantou as múltiplas esferas da vida.

A revolução científica proclamada pela modernidade, pelas vias da negação do senso comum e a consagração da significação da ciência, é considerada por Hissa (2006) como a primeira ruptura epistemológica expressiva do pensamento cartesiano. Distintos pela sua natureza de racionalidade, o imaginativo, condição primária para qualquer processo de criação humana, é sumariamente suplantado pelos caminhos metodológicos da objetividade.

\footnotetext{
1 Para melhor compreender a modernidade, nos pautamos em Hissa (2006) que busca defini-la para além de um processo histórico, mas também como um conjunto de valores que perpassam pela imaterialidade da vida: “[...] origens ou marcos pós-medievais; tempo das explorações intercontinentais, da ampliação do conhecimento dos territórios, dos povos e das descobertas; tempo da gênese da ciência moderna e dos Estados modernos; tempo da divisão de tarefas, da ampliação, da produtividade e da produção; tempo histórico da expectativa de progresso estendido a todos. [...] É um tempo de uma cultura, de uma ética, de um conjunto de valores.” (HISSA, 2006, p. 62).
} 
A ciência desenvolve-se a partir de uma concepção filosófica compatível com a realidade em processo de edificação: o positivismo. Limites são impostos à imaginação, na expectativa de que se construam os pretendidos caminhos do rigor, na indiscriminada procura da objetividade como estratégia de solução de "erros científicos”. (HISSA, 2006, p. 58).

A devida aproximação do pensamento moderno com as amarras da objetividade intenta distanciar o homem e a mulher cientista da sua própria natureza afetiva e subjetiva. O rigor do método como perspectiva interpretativa de mundo julga qualquer tentativa de desvio normativo, ou como Hissa (2006, p. 58) prefere designar de "observar cientificamente" a realidade, como não científico ou discurso ilusório.

As percepções e interações afetivas entre o sujeito e o mundo, a imaginação, a narrativa literária, a poesia, a música, o desejo, a utopia e a distopia, o cinema ou qualquer expressão artística e subjetiva que não se vincule a um proceder científico, não deve ser considerado um saber postulado pela ciência moderna.

Mas o que é a ciência sem a criação? E o que é a criação sem a imaginação? Como distanciar o sujeito do objeto de estudo? Como não compreender que o sujeito possui uma trajetória espacial, histórica, social, política e cultural que constrói sua percepção de si e sobre o mundo? Como ser imparcial na ciência? E na arte? A disjunção entre objetivo e subjetivo, arte e ciência, "produz um discurso que se pretende rigoroso, anti-literário, sem imagens nem metáforas, analogias ou outras figuras de retórica..." (SANTOS, 1989, p. 34). A escrita, enquanto processo criativo, e o próprio ato de reflexão são também a arte de se reinventar. ${ }^{2}$ (HISSA, 2006).

A Geografia, não ausente no contexto do pensamento moderno, inseriu-se na lógica da racionalidade, distanciando-se da arte e da filosofia. "A meu ver, o maior erro que a geografia cometeu foi o de querer ser ciência, em vez de ciência e arte. Ela abandonou a literatura, mudou a sua forma de escrever e sucumbiu ao método de pensar científico.” (SANTOS apud HISSA, 2006, p. 67). Enquanto ciência sobre uma razão objetiva e com o discurso de quantificação espacial dos fenômenos, o desabono da emoção e da subjetividade como parte integrante do processo criativo condicionou-a ao ato inorgânico e mecânico de ler, interpretar e compreender o mundo.

Como recurso metodológico de apreensão, prática e contestação dos fenômenos sociais e ambientais, a descrição da paisagem pelos geógrafos e geógrafas reproduzidos na lógica de uma ciência moderna engendrou uma teoria calcada na experiência ocularcêntrica em detrimento de um sujeito participante e ativo no processo da produção do conhecimento. Sobre esta base epistêmica, produziu-se uma "metageografia de corpos passivos" (AZEVEDO, 2009, p. 11), cujo espaço se constituiu enquanto

\footnotetext{
2"Todas as grandes realizações da ciência, todas as mais estupendas descobertas, foram, simultaneamente, fundamentadas na obstinação e no sonho, na capacidade de articulação intelectual e na fantasia que idealizam um mundo melhor a ser descortinado pelo esforço criativo." (HISSA, 2006, p. 61).
} 
uma superfície de representação transparente, ilusória, planificado, independente dos diferentes corpos e sujeitos.

\begin{abstract}
Erguida como um poderoso campo epistémico dentro do qual através desta superfície uma realidade objectiva se abre a um olho inocente, "o mito de uma superficie de visualização pura como linguagem pura" alicerçou um regime de conhecimento assente sobre a ideia de um olho absoluto. A complexa interacção entre linguagem e visão que estrutura a ciência moderna, estabelece assim uma dialéctica entre palavra e imagem como forma de aceder "à mudez dos objetos". [...] Nesse processo, aquilo que um campo anónimo de visão anunciava (a superfície empírica de visualização) era a própria descorporização deste Olho absoluto da "carne do mundo" e da experiência vivenciada. (AZEVEDO, 2009, p. 40-41).
\end{abstract}

A observação, pautada na contemplação da paisagem enquanto perspectiva dominante de se (re)produzir conhecimento geográfico, resultou no que Duncan e Ley (1993) defendem como uma naturalização das representações com ênfase no visual e, especialmente, nos discursos de mimese, distanciando qualquer tentativa de se compreender o mundo a partir de outras propostas, tal como a perspectivação do corpo enquanto ser ativo no processo de subjetivação nas múltiplas escalas do espaço geográfico.

Esta outra sensibilidade de apreender, refletir e agir no e sobre o espaço geográfico a partir da não hierarquização dos sentidos, o olhar como instância primária e primordial de objetificação da paisagem, explora o constante diálogo entre a produção da experiência do sujeito e a sua atuação no mundo. Não depreciamos, neste trabalho, a importância da objetivação da ciência, mas traçamos caminhos através da subjetivação da experiência que está e atravessa no/o corpo como instância atuante e política na vida.

Assim pensamos a relação afetiva e transdisciplinar ${ }^{3}$ que perpassa os caminhos confluentes entre a Geografia e a linguagem cinematográfica. Os filmes possuem a íntima capacidade de nos atravessar e propor reflexões sobre as múltiplas escalas das interações espaciais e entre os sujeitos. A análise do cinema, como proposta teórica e metodológica para compreender a cidade-personagem a partir de uma leitura geográfica, é aqui discutida no esforço de articular a paisagem fílmica como experiência sensorial perspectivada na construção social, política, econômica e cultural do sujeito, expectador participante e personagem, mais do que o olhar físico da contemplação. O que nos permite aproximar os filmes como instâncias do devir, de universos criados sobre e a partir da realidade que experienciamos.

\footnotetext{
${ }^{3}$ Corroboramos com Hissa (2006) ao buscar definir a transdisciplinaridade a partir de Guattari, que a chama de "reinvenção permanente da democracia, nos vários estágios do campo social. [...] não somente como um movimento de apropriação, por uma disciplina, de discursos referentes a áreas afins de conhecimento, mas também como um movimento de apropriação de discursos e de práticas, pela sociedade. Trata-se, nesses termos, de uma aproximação simultânea entre os diversos campos do saber, e entre eles e a sociedade; ou ainda, de simultânea ruptura das fronteiras disciplinares e dos limites entre ciência e sociedade." (HISSA, 2006, p. 107).
} 


\section{ENTRE OS CAMINHOS DA LINGUAGEM CINEMATOGRÁFICA E AS GEOGRAFIAS DE CINEMA}

O cinema é uma fonte imensurável de experiências geografias. Não há limites, meios e fins para se propor uma interpretação geográfica sobre um filme. Se tomarmos como exemplo uma ficção ou documentário qualquer, é possível reconhecermos neles múltiplas discussões no âmbito espacial, social, cultural, político, racial, estético, arquitetônico. Um universo complexo e diversos ainda pouco explorado pela Geografia brasileira.

Dentre os diversos caminhos de leituras e interpretações geográficas sobre os filmes, optamos neste trabalho por tomar a cidade, enquanto forma e discurso fílmico, como a intersecção de experiências possíveis entre esses dois saberes aparentemente tão distantes e divergentes. Buscamos apresentar as confluências teórico-metodológicas para se pensar a paisagem urbana cinemática e a maneira como a mesma pode transformar-se em cidade-personagem. Ao longo do texto, tensionamos autores de ambas as perspectivas para alcançarmos a reflexão aqui proposta: não há como produzirmos uma discussão geográfica sobre o cinema sem a potência da transdisciplinaridade.

Dessa forma, concordamos com Oliveira Júnior (1999) sobre a sua definição de filme enquanto duração; no entanto, também gostaríamos de acrescentar uma instância ainda mais profícua para compreendê-los: a experiência.

Um filme não termina. Também não começa. Ele dura. É como a chuva. Passa. Escorre. Penetra e fecunda. Carrega e destrói. É múltiplo e único. Quando termina é que se tem de novo a consciência clara. Durante o filme vivemos a opacidade e a fluidez. Enquanto chove olhamos pela janela os contornos moventes do mundo. Se nos permitimos molhar são nossos contornos que se moverão. Devemos nos permitir ao filme. Entregarmos nosso ser ao outro personagem que brilha diante de nós. (OLIVEIRA JÚNIOR, 1999, p. 6).

Assistir a um filme é, também, entregar-se ao desconhecido, é debruçar-se sobre o outro sem saber a finalidade da experiência, pois o que nos atravessa é o próprio ato de sentir e vivenciar o durante. É jogar-se ao acaso. É, portanto, um instante mútuo e único de experiência entre o espectador e a tela. Também não consideramos o filme enquanto mimese da realidade. Concordamos com Costa (2013) ao defini-lo enquanto uma obra artística que atravessa significados intertextuais que pode ser apreendido em face de outras representações e realidades carregados de ideologias.

Nas palavras de Bondía (2002), que nos soa como poesia, o entregar-se ao filme nos exige,

[...] parar para pensar, parar para olhar, parar para escutar, pensar mais devagar, olhar mais devagar, e escutar mais devagar; parar para sentir, sentir mais devagar, demorar-se nos detalhes, suspender a opinião, suspender o juízo, suspender a vontade, suspender o automatismo da ação, cultivar a atenção e a delicadeza, abrir os olhos e os ouvidos, falar sobre o que nos acontece, aprender a lentidão, escutar os outros, cultivar a arte do encontro, calar muito, ter paciência e dar-se tempo e espaço. (BONDÍA, 2002, p. 24). 
Nunca estamos sozinhos no ato de se assistir a um filme, mesmo quando não há ninguém ao lado, temos sempre a companhia de nós mesmos. Levamos toda a nossa carga histórica, social, política, econômica e cultural, que condiciona a maneira como vamos experienciar cada obra fílmica, e as confrontamos com as imagens dadas. Consentimos com Queiroz Filho (2011) sobre a maneira como as imagens ressoam em nós, em nosso corpo, e assim, nessa relação mútua e recíproca, criamos outras carregadas de sentidos.

O cinema é capaz também de nos transportar, sem saímos da poltrona, para um outro mundo de possibilidades infinitas, cujo espaço e o tempo possuem uma organização particular em cada narrativa. E é por meio das narrativas que os/as cineastas constroem novos universos, novas cidades e metrópoles, organizados imageticamente por símbolos que atravessam o nosso imaginário confluídos por metáforas.

Contudo, o espaço urbano percebido e experienciado em tela não corresponde diretamente com aquele vivenciado em nosso cotidiano. Podemos associar situações e formas simbólicas similares com a realidade, mas não devemos objetivar ou mesmo reduzir o espaço fílmico a um significado único, pois o mesmo possui uma capacidade múltipla de subjetivação.

A paisagem capturada pela câmera, entre prédios, ruas, avenidas, rios, mares e florestas, sofre distorções próprias da tecnologia de filmagem. Os diferentes ângulos, os filtros adicionados às lentes, a distância focal, a profundidade de campo, todos esses aparatos técnicos alteram a paisagem que está sendo capturada pela câmera, na qual já não pertence mais ao movimento do real. No ato da transfiguração imagética, o real engendra ecos de evidências “do tempo, do lugar, das relações sociais e culturais de onde ele foi capturado" (QUEIROZ FILHO, 2011, p. 64) e ressoa nas imagens.

Dialogamos com Pasolini (1982), Bachelard (2005) e Queiroz Filho (2011) para compreendermos a significação do real. As imagens, enquanto ecos do real, são compostas por ressonâncias que transpassam a conjuntura do espaço e do tempo. Debruçar-se sobre um filme é ser atravessado por essas ressonâncias contidas nas obras fílmicas e que também atuam e são transformadas por aqueles de quem o assiste. Somos intrinsecamente espectadores atuantes no cinema, pois ressignificamos, através das ressonâncias que as imagens nos provocam pelos caminhos da imaginação, as imagens estabelecidas dos filmes. Em consequência, recriamos o real a partir da conjectura de sermos sujeitos sociais corporificados.

E a narrativa é também a base do processo de construção das ressonâncias das imagens, pois com ela somos afetados por identificações mais singelas de comportamento e personalidade dos personagens, seja pela forma como eles se vestem, andam ou mesmo falam. E para narrar uma história, tanto nos moldes do cinema clássico quanto do contemporâneo, o cinema descreve as situações dramáticas das cenas em quadros, atos e sequências. 
A forma inicial de significação em um filme dá-se nas relações estabelecidas entre os objetos e personagens presentes num único enquadramento realizado pela câmera. À esquerda ou à direita de, ao centro, ao fundo ou em primeiro plano, maior ou menor que, acima ou abaixo de, mais ou menos iluminado que, são dados significativos para o entendimento fílmico. (OLIVEIRA JÚNIOR, 1999, p. 11).

Os dispositivos utilizados pelo cinema para se narrar uma história possuem intrinsecamente uma significação para descrever uma ação dramática. Como comenta Oliveira Júnior (1999), o enquadramento escolhido pelos/as cineastas é responsável por produzir sentidos múltiplos e ilusões. Tomamos como exemplo os planos: primeiríssimo, médio e geral. Enquanto o primeiro apresenta o olho de um personagem em seu mais íntimo detalhe, de cores azuis cintilantes que nos encara veemente, se a câmera ousar afastar-se um pouco mais do objeto filmado, em contexto de médio plano, tomamos consciência das suas características: roupa, cor do cabelo, gênero masculino. Por que o personagem está imóvel encarando-nos? Se a câmera ousar afastar-se do objeto ainda mais, demonstrando um plano geral de cena, podemos perceber que se trata de um homem imóvel, deitado na cama de lençóis brancos, provavelmente morto, pois o olho não demonstra movimento.

A noção de campo relaciona-se com a noção de enquadramento, portanto de espaço. Ora, enquadrar é delimitar o campo a partir do olhar da câmera. Por isso na literatura cinematográfica, o cinema é constantemente descrito pela sua capacidade de fragmentação: recortar o espaço filmado ou reunir as cenas fragmentadas na montagem, compondo uma narrativa de movimento. Se entendemos o campo como o fragmento do que é filmado a partir de um ponto de vista, a câmera, como podemos, durante o filme, sermos tomados também pelo espaço que está para além do enquadramento? O espaço diegético não enquadrado, ou fora-de-campo, também possui um objetivo narrativo, uma continuidade sonora e imagética que conduz nossa imaginação durante o filme.

Assim, a linguagem cinematográfica, com toda a sua riqueza técnica e conceitual, nos permite tomar interpretações geográficas acerca dos filmes. Escolher uma, duas ou mais obras fílmicas para se propor uma leitura é compreender a capacidade que o cinema possui de realizar uma grafia de mundo. Corroboramos com Oliveira Júnior (1999) e Queiroz Filho (2011) ao tratamos o cinema, portanto também o ato de se assistir a um filme, como uma experiência intimamente geográfica. Com isso, enriquecemos as significações das obras fílmicas admitindo a sua potente dimensão espacial.

$\mathrm{O}$ ato de se interpretar um filme no âmbito de uma espacialidade é tratá-lo ainda enquanto um recurso metodológico para compreender os fenômenos geográficos. Paisagem, região, território, espaço e lugar são conceitos possíveis de serem apreendidos através dos filmes de ficção e documentário. Podemos ir além dos conceitos e adentramos nas questões de gênero e das etnicidades, das contradições do espaço urbano, da crise do mercado imobiliário, da ascensão da extrema direita no mundo, entre outras tantas temáticas e recortes que os filmes são capazes de nos atravessar. 
Têm-se, portanto, a partir da transdisciplinaridade entre os estudos geográficos e a linguagem do cinema, o que Oliveira Júnior (2005) definiu como Geografias de Cinema, cuja existência é calcada nos textos geográficos que apresentam as relações entre imagens, sons e as múltiplas significações em que os filmes ecoam enquanto arte e indústria.

Essa é uma proposta de pesquisa das imagens e sons fílmicos, baseada na ideia de que os filmes estão a nos propor pensamentos acerca do espaço, não só resultantes das alusões literais - por verossimilhança visual e sonora - a uma realidade existente além cinema, mas também de movimentos imaginativos resultantes do encontro inusitado nessas imagens e sons de outras formas de conceber e viver o espaço como dimensão da existência humana. (OLIVEIRA JÚNIOR, 2005, p. 28).

As relações imaginativas e interpretativas acontecem a partir do confronto entre o contexto de mundo do espectador e o próprio filme. Nosso aporte cultural recria o real das imagens e somos também afetados por elas. Dessa forma, as geografias de cinema confluem também para compreender o espaço na qual os personagens dos filmes atuam, pois é nesse universo fílmico em que os territórios, os lugares e as paisagens adquirem significações.

Contudo, conforme pontua Oliveira Júnior (1999), essas Geografias de Cinema também não podem ser restritas somente ao caráter subjetivo e imaginativo de interpretação. É necessário compreender que as imagens e os sons dos filmes contêm uma materialidade objetiva e real para os personagens das tramas; eles agem no universo que dura, com começo, meio e fim, naquele mundo cujas leis da gravidade traduzem as limitações da sua própria criação.

Por fim, somos nós, seres corporificados, que produzimos interpretações geográficas das imagens e dos sons dispostos pelos filmes. Há geografias presentes no universo cinematográfico, assim como há geógrafos e geógrafas capazes de entregar-se ao acaso fílmico e, com ele e a partir dele, obter significados múltiplos de interpretações de mundo.

\section{INTERPRETAÇÕES GEOGRÁFICAS SOBRE A CIDADE-PERSONAGEM}

A priori, sem a pretensão de elucidar qualquer hipótese baseada numa intensa reflexão teórica, pensamos que a cidade e o cinema possuem uma característica em comum: a sua capacidade de fragmentação. Enquanto o cinema é fragmentado por reunir um conjunto de cenas e sequências e, assim, conduzi-las a um ritmo de narrativa através da montagem e com duração específica, a cidade é fragmentada pelas relações de poder hierárquicas exercidas no seu espaço, resultando também em grupos culturais de ocupação no que concerne à apropriação do urbano a partir das práticas espaciais.

Para além da característica da fragmentação, podemos apontar outra semelhança entre a cidade e o cinema: o seu caráter subjetivo e corporificado de vivenciá-los. Determinados corpos que destoam da normatização social estabelecida pelas forças dominantes provocam tensões no espaço a partir das suas trajetórias sociais, políticas, econômicas e culturais. Assim também como cada filme ressoa de 
maneira particular em cada corpo. Podemos auferir, portanto, que há caminhos possíveis para se pensar as semelhanças, e as diferenças, entre a cidade e o cinema, seja na forma como nos relacionamos ou na maneira em que são constituídos.

E de tanto filmá-las, o cinema ainda é capaz de falar sobre si, em consequência da sua gênese ser intrinsecamente urbana, ou mesmo sobre as cidades que estão sendo representadas ou criadas em tela, transformando-as através do seu potencial imaginativo. Nas palavras de Tavares (2015), "o cinema narra, através dos seus dispositivos, a cidade" (TAVARES, 2015, p. 256) e a devora com sua voracidade de espetacularização da vida diante dos olhos, dos sentidos e dos corpos de cada espectador.

Ao ser capturada pelas lentes da tecnologia cinematográfica, a cidade transfigura-se em texto, ou hipertexto que, segundo Comolli (2008), relaciona-se e se converte numa rede de signos passíveis de múltiplas interpretações, até mesmo geográficas. A câmera, que conjuga um ponto de vista carregado de intenções e ideologias, fragmenta o espaço e o tempo da vida social a partir do enquadramento e decide o que deve ou não, como o fora-de-campo, ser apreendido em favorecimento da narrativa.

As cidades que vemos nos filmes, apesar das semelhanças das formas espaciais, são diferentes daquelas nas quais nos relacionamos no cotidiano. Enquanto a cidade não-ficcional é o espaço das relações mútuas e da alteridade entre os seus habitantes, a ficcionalizada se apropria das vivências e experiências entre os sujeitos para produzir uma outra realidade a partir da linguagem cinematográfica.

A origem dessa relação mútua entre a cidade e o cinema não provém deste século. Há, na história da indústria cinematográfica, uma longa trajetória de filmes que abordam o espaço urbano e as suas problemáticas, segundo contextos espaciais e temporais vivenciados por cada cineasta. Durante e após a década de 1920, por exemplo, houve um forte movimento cultural de filmes com temáticas sobre a ode às cidades, tais como "Nova Iorque, a magnífica" (Paul Strand e Charles Sheeler, 1921), "A ilha de vinte e quatro dólares" (Robert Flaherty, 1924), "Paris que dorme" (René Clair, 1924), "Nada além das horas" (Alberto Cavalcanti, 1926), "Berlim, sinfonia de uma metrópole” (Walter Ruttman, 1927), “A propósito de Nice” (Jean Vigo, 1929), “O homem com a câmera” (Dziga Vertov, 1929), “Douro, Faina Fluvial” (Manoel de Oliveira, 1931), dentre outros. Esses filmes, contudo, não oportunizam a cidade apenas como plano de fundo das narrativas, mas a consideram também como personagens imprescindíveis para se contar as suas respectivas histórias.

No contexto dos filmes acima, a cidade-personagem é descrita com imagens que demonstram uma verborragia iminente de letreiros publicitários, comumente reconhecidos pelas logomarcas das famosas corporações internacionais, de arquitetura geométrica dos imponentes arranha-céus, fábricas e ruas ocupadas por intensos fluxos de pedestres cujos sujeitos são ofuscados em detrimento da mecanização da vida e da valorização da máquina, da indústria, do cotidiano como engrenagem da metrópole moderna. "A agitação urbana torna-se a figura privilegiada da emoção cinematográfica." (COMOLLI, 2008, p. 183). 
Segundo Brait (1985), personagens são seres do universo da ficção, complexos em seu constructo, comumente associados à forma humana e que possuem especificidades psicológicas e corporais, através das suas ações em detrimento da narrativa. Ao vincularmos a concepção de cidadepersonagem, acrescentamos uma outra camada para se pensar os personagens ficcionais: a partir das representações. A capacidade na qual a cidade, em sua forma espacial e cultural, age e torna-se presente através das ações, falas e situações dramáticas dos personagens ou protagonistas.

É como se a cidade, apesar de não possuir um corpus físico na trama, ecoasse e se expressasse através dos personagens humanos ou dos seus conflitos dramáticos. Assim, nas circunstâncias em que os filmes possuem uma cidade-personagem, a narrativa resume-se em discorrer tanto sobre elas quanto sobre qualquer outro personagem presente na trama. Sentimos a necessidade de ressaltar também que a utilização do "hífen" para discorrer sobre a cidade enquanto personagem, cidade-personagem, se refere pela própria capacidade dialética da mesma de conter em si o seu papel de personagem na trama, mas também de exercer a sua função de locação, plano de fundo ou lócus do acontecer da vida urbana.

Apesar de o recorte temporal ser importante para se conduzir uma narrativa, ainda se faz necessário pensar na localização espacial em que a trama acontece. Todo filme, e aqui não temos como fugir da generalização, é realizado em algum lugar específico, seja ele produzido em estúdios ou localizado geograficamente no globo. E a paisagem, de fato, é o entremeio imediato de contato visual que estabelecemos com as obras fílmicas. A cidade é rapidamente apresentada, no universo cinematográfico, a partir das suas formas urbanas e culturais.

Contudo, ao tratarmos da cidade-personagem, a forma urbana, ou os ícones urbanos que estão presentes em nossas memórias e nos cartões-postais das grandes metrópoles, não necessariamente é a única maneira de apresentá-la. Os demais personagens da trama podem discorrer sobre ela a partir dos seus conflitos dramáticos, através dos diálogos ou das suas ações.

Tomemos como exemplo uma das obras fílmicas citadas neste trabalho, "Medianeras: Buenos Aires da Era do Amor Virtual" (2011), do cineasta argentino Gustavo Taretto. As primeiras cenas do filme apresentam uma cidade de muitos prédios, antenas e de um agridoce céu azulado, sem estrelas e com nuvens acinzentadas. É interessante ressaltar como as cores são capazes de nos fornecer metáforas, subtextos ou fortalecer ainda mais o discurso da obra. O azul em "Medianeras" imprime uma relação de tristeza, frieza e distanciamento, palavras e sentimentos que estão presentes ao longo da narrativa. Seriam essas características uma descrição da própria cidade-personagem?

Uma voz masculina ecoa sobre a imagem de uma cidade silenciosa. Um personagem, o qual tomamos, ao longo da história, como um dos protagonistas da trama, fala sobre uma Buenos Aires superpovoada, de um país deserto. Uma cidade em cujo espaço geográfico se erguem anualmente dezenas de prédios sem nenhuma legislação ou controle. Prédios de tamanhos e formas diversas, assimétricos e de irregularidades estéticas e éticas que, segundo o protagonista, reflete diretamente na 
forma como os habitantes se relacionam. Uma cidade sem planejamento, assim como a vida daqueles que a vivem em seu cotidiano.

Nas imagens que se sucedem, não há sinal de vida humana, apenas a cidade na sua forma espacial. No entanto, é interessante pontuar que ao longo dos cinco minutos da primeira sequência, ao falar de Buenos Aires, o filme não se utiliza de nenhuma imagem que nos remete aos símbolos icônicos do turismo da cidade não ficcional. Não há a presença do Obelisco, da Casa Rosada, do Teatro Colón ou dos estádios de futebol. O que vemos é uma cidade sendo-nos apresentada para além da forma e a partir do monólogo do protagonista.

Ao longo do filme, notamos que Buenos Aires não é somente uma locação dentro da narrativa fílmica. A obra produz um discurso sobre ela: uma cidade que é capaz de isolar as pessoas, que cultiva a solidão entre os seus habitantes e que, pela sua magnitude e um modo de vida voltado exclusivamente para o trabalho, adoece e exerce uma frieza nas relações interpessoais. E só percebemos esse discurso na medida em que os protagonistas se relacionam afetivamente com a própria cidade-personagem.

Afetos estes que não necessariamente resultam em experiências positivas. Para os personagens, viver numa grande metrópole, especialmente nesta Buenos Aires da ficção, é entregar-se à solidão. $\mathrm{O}$ cinema tem a capacidade de deslocar as pessoas, personagens ou espectadores, entre espaços e lugares. Os lugares fílmicos, aqueles em que há uma relação de afetos entre os seres que os habitam e os locais narrativos, são construídos através das vivências e transitoriedade dos personagens. São eles que dão existência e sentido à cidade que nos é apresentada em imagens e sons.

Ao longo da trajetória do pensamento geográfico, o conceito de lugar foi articulado para compreender os fenômenos a partir da escala global.

Por ora, tenho assistido ao sugamento do conceito de lugar para o interior de um pensamento global, generalizado por excelência, ao dizer que no lugar temos o global. Subordinação da experiência, concreta e corporal de cada um, às explicações dadas pelos especialistas acadêmicos que ao generalizar, na busca da invenção de conceitos auxiliadores para se entender melhor o mundo no qual vivemos, devem apagar as marcas do inusitado, do ocasional, do distinto, que apesar de diferir continua permanecendo como igual. (OLIVEIRA JÚNIOR, 2005, p. 31).

Pensamos que há um problema escalar que envolve o entendimento do lugar nas suas múltiplas instâncias do acontecer da vida. Não descartamos a sua construção teórica e metodológica, pois há nela uma sensibilidade, beleza e importância para se pensar o lugar frente às dinâmicas exercidas da globalização nas diversas escalas do cotidiano. Contudo, a maneira como esse discurso é exercido nos trabalhos acadêmicos, negligencia as possibilidades de alcançarmos a subjetividade da experiência de cada indivíduo.

E como pensar a relação dos personagens com os lugares filmicos sem acessar a subjetividade e os afetos exercidos no espaço durante o acontecimento da vida cotidiana? A relação entre os personagens e o lugar fílmico, permeado de afetos, se dá justamente e propriamente na 
microescala do cotidiano, da experiência, a priori, concreta e corporal. É a partir dessa relação que emerge, portanto, a cidade-personagem permeada de significações. Cidade-personagem que possui características próprias, que exerce uma função narrativa dramática na trama e que, muitas das vezes, pode-se até mesmo tornar-se protagonista do próprio filme, pois sem ela, ou se a deslocássemos para outra localização, mudaríamos todo o contexto narrativo da obra.

\section{CONSIDERAÇÕES FINAIS}

Há múltiplos caminhos para se propor uma leitura das cidades no âmbito da ciência geográfica. Neste trabalho, buscamos tensionar os saberes entre a linguagem cinematográfica e a Geografia para propor intepretações acerca dos filmes e da maneira como as cidades são apresentadas e (re)produzidas por eles. Com isso, partimos da transdisciplinaridade enquanto perspectiva metodológica para questionar o ato do fazer científico robusto e inflexível da modernidade, cuja objetividade pareceu tomar, ao longo da história da ciência, o único horizonte possível para se ler, pensar e refletir sobre a realidade.

Assim, adotamos o cinema enquanto uma ponte subjetiva que atravessa afetivamente aqueles que adentram no seu universo do acaso, do desconhecido, ao assistir um filme. Cada sujeito, não restrito à neutralidade do olhar, corporificado no espaço geográfico com trajetórias sociais, políticas, econômicas e culturais, produz imaginários e recria realidades a partir da experiência fílmica. Dessa forma, o ato de se assistir a um filme torna-se também uma experiência geográfica, pois admitimos que nele há um confronto de perspectivas espaciais estabelecidas entre a obra e o espectador.

E as cidades, apreendidas neste trabalho não apenas como configuração cênica, são capazes de tornar-se personagens na trama e, assim, serem (re)produzidas a partir do imaginário e das ressonâncias que atravessam afetivamente os filmes. A cidade fílmica, enquanto cidade-personagem, expressa-se através dos demais personagens que compõem a trama, seja não só pelos diálogos ou pelas situações dramáticas, mas também, a priori, pela sua própria capacidade de representação de si a partir do outro. E é nessa relação afetiva entre os protagonistas e o espaço diegético que a cidade-personagem se faz presente nos filmes, evocando o lugar fílmico imbricado de símbolos e significações.

\section{REFERÊNCIAS}

AZEVEDO, A. F.; PIMENTA, J. R.; SARMENTO, J. As geografias culturais do corpo. In: AZEVEDO, A. F.; PIMENTA, J. R.; SARMENTO, J. Geografias do corpo: ensaios de geografia cultural. Porto: Figueirinhas, 2009. cap. 1, p. 11-30.

AZEVEDO, A. F. Desgeografização do corpo. Uma política de lugar. In: AZEVEDO, A. F.; PIMENTA, J. R.; SARMENTO, J. Geografias do corpo: ensaios de geografia cultural. Porto: Figueirinhas, 2009. cap. 2, p. 31-80. 
BACHELARD, G. A poética do espaço. 2. ed. Rio de Janeiro: Eldorado, 2005. 256p.

BONDÍA, J. L. Notas sobre a experiência e o saber da experiência. Revista Brasileira de Educação, n. 19, p. 20-28, 2002.

BRAIT, B. A personagem. 1. ed. São Paulo: Ática, 1985. 176p.

BRUNO, G. Atlas of Emotion: journeys in art, architecture and film. 1. ed. New York: Verso, 2002. 496p.

COMOLLI, J. A cidade filmada. In: COMOLLI, J. Ver e poder: a inocência perdida. Cinema, televisão, ficção, documentário. Belo Horizonte: UFMG, 2008. cap. 14, p. 179-185.

COSTA, M. H. B. V. A cena espetacular: cinema e arquitetura urbana na contemporaneidade. Revista ArtCultura, Uberlândia, v. 13, n. 23, p. 155-165, 2008.

COSTA, M. H. B. V. Geografia cultural e cinema: práticas, teorias e métodos. In: ROSENDHAL, Z.; CORREAA, R. L. Geografia Cultural: uma antologia. Rio de Janeiro: EDUERJ, 2013. p. 247264.

DUNCAN, J.; LEY, D. Place, culture and representation. 1. ed. London: Routledge, 1993. 352p.

QUEIROZ FILHO, A. C. A Geografia vai ao cinema. Resgate: Revista Interdisciplinar de Cultura, Campinas, v. 9, n. 21, p. 61-70, 2011.

HISSA, C. E. V. A mobilidade das fronteiras: inserções da Geografia na crise da modernidade. 1. ed. Belo Horizonte: UFMG, 2006. 316p.

OLIVEIRA JR., W. M. Chuva de cinema: natureza e cultura urbana. 1999. 162 f. Tese (Doutorado em Educação) - Faculdade de Educação, Universidade Estadual de Campinas, Campinas, 1999.

OLIVEIRA JR., W. M. O que seriam as geografias de cinema? Revista Txt: leituras transdisciplinares de telas e textos, Belo Horizonte, v. 1, n. 2, p. 27-33, 2005.

PASOLINI, P. P. Empirismo herege. 1. ed. Lisboa: Assírio e Alvim, 1982. 251p.

SANTOS, B. S. Introdução a uma ciência pós-moderna. 1. ed. Rio de Janeiro: Graal, 1989. 176p.

TAVARES, M. Cidade e cinema: que importa ao exilado que as cores sejam falsas. In: AZEVEDO, A. F.; RAMÍREZ, R. C.; OLIVEIRA JR., W. M. Intervalo entre geografias e cinemas. Braga: UMDGEO, 2015. cap. 8, p. 251-270. 